\title{
Complete Genome Sequence Analysis of Two Divergent Groups of Sweet potato chlorotic fleck virus Isolates Collected from Korea
}

\author{
Hae-Ryun Kwak ${ }^{1}$, Jaedeok Kim ${ }^{1}$, Mikyeong Kim ${ }^{1}$, Jang-Kyun Seo ${ }^{2}$, Jeong-Soo Kim ${ }^{3}$, and Hong-Soo Choi ${ }^{1 *}$ \\ ${ }^{1}$ Crop Protection Division, National Institute of Agricultural Science, Wanju 55365, Korea \\ ${ }^{2}$ Graduate school of International Agricultural Technology, Seoul National University, Pyeongchang 25354, Korea \\ ${ }^{3}$ Department of Plant Medicine, Andong National University, Andong 36729, Korea
}

(Received on March 11, 2018; Revised on June 10, 2018; Accepted on July 29, 2018)

The Sweet potato chlorotic fleck virus (SPCFV), of the genus Carlavirus (family Betaflexiviridae), was first detected as one of several viruses infecting sweet potatoes (Ipomea batatas L.) in Korea. Out of 154 sweet potato samples collected in 2012 that were showing virus-like symptoms, 47 (31\%) were infected with SPCFV, along with other viruses. The complete genome sequences of four SPCFV isolates were determined and analyzed using previously reported genome sequences. The complete genomes were found to contain 9,104-9,108 nucleotides, excluding the poly-A tail, containing six putative open reading frames (ORFs). Further, the SPCFV Korean isolates were divided into two groups (Group I and Group II) by phylogenetic analysis based on the complete nucleotide sequences; Group I and Group II had low nucleotide sequence identities of about $73 \%$. For the first time, we determined the complete genome sequence for the Group II SPCFV isolates. The amino acid sequence identity in coat proteins (CP) between the two groups was over $90 \%$, whereas the amino acid sequence identity in other proteins was less than $80 \%$. In addition, SPCFV Korean isolates had a low amino acid sequence identity (61\% CPs and $47 \%$ in the nucleotide-binding protein $[\mathrm{NaBp}]$ region) to that of Melon yellowing-associated virus (MYaV), a typical Carlavirus.

Keywords : Complete genome sequences, phylogenetic

\footnotetext{
*Corresponding author.

Phone) +82-31-290-0430, FAX) +82-31-290-0434

E-mail)hschoi@korea.kr

(c) This is an Open Access article distributed under the terms of the Creative Commons Attribution Non-Commercial License (http:// creativecommons.org/licenses/by-nc/4.0) which permits unrestricted noncommercial use, distribution, and reproduction in any medium, provided the original work is properly cited.
}

Articles can be freely viewed online at www.ppjonline.org. analyses, sweet potato chlorotic fleck virus

Handling Associate Editor : Ju, Ho-Jong

Sweet potatoes (Ipomea batatas L., family Convolvulaceae) are grown extensively throughout tropical and temperate regions and are the seventh most important food crop in the world in terms of production. According to Food and Agriculture Organization Corporate Statistical Database (FAOSTAT) data from 2014, sweet potatoes have been cultivated across 8.4 million ha, with the production of 107 million tons worldwide. In Korea, sweet potatoes are cultivated across 20,515 ha, resulting in the production of 322,071 tons, with output increasing every year (FAOSTAT, 2014).

Viral diseases affecting sweet potatoes have become widespread, causing serious crop losses around the world. To date, more than 30 viruses have been identified that infect sweet potatoes (Brunt et al., 1996; Clark et al., 2012). In Korea, eight viruses have been reported, including the Sweet potato feathery mottle virus (SPFMV), Sweet potato virus C (SPVC), Sweet potato virus G (SPVG), Sweet potato virus 2 (SPV2), and Sweet potato latent virus (SPLV) belonging to the genus Potyvirus in the family Potyviridae; Sweet potato leaf curl virus (SPLCV), belonging to the genus Begomovirus in the family Geminiviridae; Sweet potato symptomless virus 1 (SPSMV-1), belonging to the genus Mastrevirus in the family Geminiviridae; and Sweet potato chlorotic fleck virus (SPCFV), belonging to the genus Carlavirus in the family Betaflexiviridae (Kwak et al., 2006, 2014). Most sweet potato virus symptoms result from a mixed infection of at least two of these eight viruses (Kwak et al., 2014). Among these eight viruses, SPFMV and SPVC are very prevalent in Korea (Kwak et al., 2014).

SPCFV was first detected in sweet potatoes showing fine 
chlorotic spots in Peru. It has since been detected in several countries of South America, Asia, and South Africa, and the complete genome sequence of an isolate from Uganda has been characterized (Aritua et al., 2007). SPCFV reportedly causes a synergistic disease when sweet potatoes are co-infected with Sweet potato chlorotic stunt virus (SPCSV) (Untiveros et al., 2007). In Korea, SPCFV occurred in 31\% of samples collected from most areas of Korea in 2012 (Kwak et al., 2014). However, the incidence rates of SPCFV decreased to $0 \%$ and $2.5 \%$ in 2013 and 2014, respectively (Kim et al., 2017).

SPCFV is a positive-sense single-stranded RNA virus with a genome of approximately $9.1 \mathrm{~kb}$ that potentially includes six open reading frames (ORFs). ORF1 encodes a viral replicase (Rep), ORF2 to ORF4 encode triple gene block (TGB) proteins (TGB1, TGB2, and TGB3), and ORF5 encodes the coat protein (CP). Further, ORF6 encodes a putative nucleotide-binding protein $(\mathrm{NaBp})$ (Aritua et al., 2007).

In this study, to analyze the genetic structure and variability of Korean SPCFV isolates, we determined the complete genome sequences of four SPCFV isolates based on geographic location from sweet potato samples collected in 2012 (Kwak et al., 2014).

Total RNA was extracted from the infected sweet potato leaf, petiole, and stem samples using an Easy-spin ${ }^{\mathrm{TM}}$ total RNA extraction kit (Intron, Korea) according to the manufacturer's instructions. Reverse transcription polymerase chain reaction (RT-PCR) was performed as a two-step procedure; RT was conducted using Avian myeloblastosis virus (AMV) reverse transcriptase (Promega, USA), and PCR was carried out using high-fidelity LA taq polymerase (Takara, Japan). Specific PCR primer pairs were designed for primer walking and subsequent sequencing to obtain the complete genome sequences based on previously reported SPCFV nucleotide sequences (Table 1,2). End sequences of each RNA segment were obtained according to the $5^{\prime}$ and $3^{\prime}$ rapid amplification of cDNA ends (RACE) protocol (BM, Germany). cDNA clones containing the $5^{\prime}$ end of the genome were obtained using the Xec primer (5'-AAAGAATTCCCCCCCCCCCCC-3') and SPCFV_5'race-R primer complementary to nucleotides 262-239 of the SPCFV genome. In addition, cDNA clones containing the $3^{\prime}$ end of the genome were obtained using a SPCFV

Table 1. Full sequencing primers for Group I of SPCFV

\begin{tabular}{|c|c|c|c|c|}
\hline Fragment & Name & Sequence $\left(5^{\prime} \rightarrow 3^{\prime}\right)$ & Loci* & Size (bp) \\
\hline \multirow{8}{*}{$\mathrm{P} 1$} & spcfv-full-1f & TGCTGAAGAGGCACTATCCTCC & $86-107$ & \multirow{2}{*}{1060} \\
\hline & spcfv-full-1r & AGCAGACTGAACATCTGGCTTC & $1145-1124$ & \\
\hline & spcfv-full-2f-1 & TGCAATGATGGTACWGTCTATAGTG & $897-921$ & \multirow{2}{*}{1173} \\
\hline & spcfv-full-2r-1 & CCTTTGAGRCTTCTARWGCTTC & 2070-2049 & \\
\hline & spcfv-full-3f & ACGGGCTCATTTGGTTCTTG & $1810-1829$ & \multirow{2}{*}{1027} \\
\hline & spcfv-full-3r & GCTTCAGTGTCCCTGGATTCAC & $2836-2815$ & \\
\hline & spcfv-full-4f & AGATGCCAAGAGATTTCCAAGAG & $2629-2651$ & \multirow{2}{*}{1050} \\
\hline & spcfv-full-4r & AGGTGCCACCTCCTCTAGCTC & $3678-3658$ & \\
\hline \multirow{8}{*}{$\mathrm{P} 2$} & spcfv-full-5f-1 & TTTGATATWTGCGGGGTGTGC & $3462-3482$ & \multirow{2}{*}{1016} \\
\hline & spcfv-full-5r & GCGAGGGCACGACATTCCT & $4477-4459$ & \\
\hline & spcfv-full-6f-1 & CAAAGTGATTATGACTCTCTGCG & $4254-4276$ & \multirow{2}{*}{1108} \\
\hline & spcfv-full-6r-1 & TCGAAGTCCTGYACAGCCTTATC & $5361-6340$ & \\
\hline & spcfv-full-7f & AGAGATTTGCAGCCATCTACCC & $5149-5161$ & \multirow{2}{*}{1027} \\
\hline & spcfv-full-7r & ATTGCATAATTATCCAGGCATTC & $6175-6153$ & \\
\hline & spcfv-full-8f & AACACTTAAGACAGAGCATGATGG & $5978-6001$ & \multirow{2}{*}{1085} \\
\hline & spcfv-full-8r & TTAGAATAGTCCGCGGGTGG & $7063-7044$ & \\
\hline \multirow{5}{*}{ P3 } & spcfv-full-9f & GGCCACAAGAAGTGAGGGG & $6894-6912$ & \multirow{2}{*}{1061} \\
\hline & SPCFV 1R & AAGGTCTGTAGTTTTCCATGTACC & $7954-7931$ & \\
\hline & SPCFV $1 F$ & ATGTTTGCTGGGGAGAGTCAGG & $7555-7576$ & \multirow{3}{*}{1038} \\
\hline & SPCFV 2F-1 & AAAGTGGAACAGGGAGCCCG & $8067-8086$ & \\
\hline & SPCFV 2R & GCTCAAAAGTACTTTAAAACATGC & 9104-9081 & \\
\hline \multirow{2}{*}{ RACE } & SPCFV 3'-F & GTGATTGGGAYYGYTGTCTT & $8718-8737$ & 387 \\
\hline & SPCFV 5'-R & GGTGAAACAGGTGAGAGGTATATC & $262-239$ & 262 \\
\hline
\end{tabular}

*Reference sequence: SPCFV- Hoima 4 (AY461421) 
Table 2. Full sequencing primers for Group II of SPCFV

\begin{tabular}{|c|c|c|c|c|}
\hline Fragment & Name & Sequence $\left(5^{\prime} \rightarrow 3^{\prime}\right)$ & Loci* & Size (bp) \\
\hline \multirow{8}{*}{$\mathrm{P} 1$} & spcfv-full-1f & TGCTGAAGAGGCACTATCCTCC & $86-107$ & \multirow{2}{*}{1060} \\
\hline & spcfv-full-1r & AGCAGACTGAACATCTGGCTTC & $1145-1124$ & \\
\hline & SPCFV(II)-2F & ATTCGCCCACCACTTAATTAGTATC & $944-968$ & \multirow{2}{*}{1089} \\
\hline & SPCFV(II)-2R & TGGTGATTCAACTGCATTCGGGTC & 2032-2009 & \\
\hline & SPCFV(II)-3F & AAGGGCAAGTGGTTTTCAAGTAAC & $1850-1870$ & \multirow{2}{*}{1032} \\
\hline & SPCFV(II)-3R & GGGCCTCATGACTACCAGAGTCAG & $2881-2858$ & \\
\hline & SPCFV(II)-4F & GCCTGAGGGGTTTCAGGAGAAGT & $2638-2660$ & \multirow{2}{*}{1103} \\
\hline & SPCFV(II)-4R & GCAGAAGGTCCAAAATGTAGTCCTT & $3740-3720$ & \\
\hline \multirow{8}{*}{$\mathrm{P} 2$} & SPCFV(II)-5F & GCAAGATCGAAGCACTCAAGGATC & $3602-3625$ & \multirow{2}{*}{744} \\
\hline & SPCFV(II)-5R & CGGAACCAAGGCTCTACACTCATC & $4483-4460$ & \\
\hline & spcfv-full-6f-1 & CAAAGTGATTATGACTCTCTGCG & $4254-4276$ & \multirow{2}{*}{1108} \\
\hline & spcfv-full-6r-1 & TCGAAGTCCTGYACAGCCTTATC & $5361-6340$ & \\
\hline & SPCFV(II)-7F & ATTGACCAATGCCGCAGAGAGG & $5126-5146$ & \multirow{2}{*}{1096} \\
\hline & SPCFV(II)-7R & GGTAGGACCTTCTCTCCCAA & $6222-6200$ & \\
\hline & spcfv-full-8f & AACACTTAAGACAGAGCATGATGG & $5978-6001$ & \multirow{2}{*}{1085} \\
\hline & spcfv-full-8r & TTAGAATAGTCCGCGGGTGG & 7063-7044 & \\
\hline \multirow{5}{*}{$\mathrm{P} 3$} & SPCFV(II)-9F & ACTACAGCCTATTTGGCCAAGC & $6738-6760$ & \multirow{2}{*}{1149} \\
\hline & SPCFV(II)-9R & GGAGATCTCACCCTGCGCA & $7887-7879$ & \\
\hline & SPCFV 1F & ATGTTTGCTGGGGAGAGTCAGG & $7555-7576$ & \multirow{3}{*}{1038} \\
\hline & SPCFV 2F-1 & AAAGTGGAACAGGGAGCCCG & $8067-8086$ & \\
\hline & SPCFV 2R & GCTCAAAAGTACTTTAAAACATGC & 9104-9081 & \\
\hline \multirow{2}{*}{ RACE } & SPCFV 3'-F & GTGATTGGGAYYGYTGTCTT & $8718-8737$ & 387 \\
\hline & SPCFV 5'-R & GGTGAAACAGGTGAGAGGTATATC & $262-239$ & 262 \\
\hline
\end{tabular}

*Reference sequence: SPCFV- Hoima 4 (AY461421)

3'-race-F primer complementary to nucleotides $8,718-8,737$ and an anchor primer (5'-GACCACGCGTATCGATGTCGACTTTTTTTTTTTTTTTTV-3').

The complete genomes of Korean SPCFV isolates ranged from 9,104 to 9,108 nucleotides, excluding the poly-A tails, and encoded six ORFs. The genomic organization of the Korean SPCFV isolates was typical for members of the Carlavirus genus. ORF1 encodes a viral replicase (2,090 aa in size), and ORF2 to ORF4 encode TGB proteins, including TGB1, TGB2, and TGB3 (240 aa, 108 aa, and 67 aa in size, respectively). ORF5 encodes the CP (299 aa), and ORF6 encodes a NaBp (133 aa). The 5' and $3^{\prime}$ non-coding regions (NCR) are 65 and 52 nucleotides in length, respectively. The full-length genome sequences are available in the GenBank database, with the accession numbers listed in Table 3.

To analyze phylogenetic relationships, the complete nucleotide sequences and deduced amino acid (aa) sequences were aligned using the ClustalX2 program and Geneious methods in Geneious Pro 8 and compared to those of previously reported isolates (Table 3). Melon yellowing-associated virus (MYaV, accession no. AY373028) was used as an outgroup. Genius Pro 8 software was used to calculate the percentages of nucleotide and aa identities. Phylogenetic analyses were performed according to the maximumlikelihood method implemented in MEGA 6 (Tamura et al., 2013). All phylogenic tests were conducted using the best substitution model for nucleotides or amino acids, with 1,000 bootstrap replicates.

The complete nucleotide and deduced aa sequences of 4 SPCFV isolates were compared to those previously reported for virus isolates. According to a previous report, SPCFV is divided geographically into African and Peruvian isolates and Asian isolates (Aritua et al., 2009). Phylogenetic analysis indicated that Korean SPCFV isolates are clustered into the Asian isolates, including Chinese, Taiwanese, and Australian isolates. Furthermore, Korean SPCFV isolates could be largely divided into two groups (Group I and Group II) (Fig. 1). The nucleotide and aa sequence identities between SPCFV isolates are summarized in Table 4. Based on the full-length and partial genome nucleotide sequences, SPCFV isolates can be split into two groups with low nucleotide sequence identities of about $73-78 \%$, while the intragroup nucleotide sequence identity 
Table 3. Database of the complete and partial nucleotide sequences of SPCFV isolates infecting sweet potato

\begin{tabular}{|c|c|c|c|c|}
\hline Virus & Isolate $^{c}$ & Origin & Genome size (nt) & NCBI accession No. \\
\hline \multirow{15}{*}{ SPCFV $^{\text {a }}$} & SC20 & Sacheon, Korea & 9,104 & KP115606 \\
\hline & UN210 & Muan, Korea & 9,104 & KP115607 \\
\hline & HN83 & Haenam, Korea & 9,104 & KP115605 \\
\hline & HG176 & Muan, Korea & 9,108 & KP715159 \\
\hline & Hoima 4 & Uganda & 9,104 & AY461421 \\
\hline & KBL38 & Uganda & & EU375903 \\
\hline & $94-15$ & Kenay & & EU375900 \\
\hline & KY5 & Kenay & & EU375904 \\
\hline & CIP & Peru & & EU375899 \\
\hline & Tar & Tanzania & & AJ781296 \\
\hline & Gwangzhu1 & China & & EU375901 \\
\hline & B-Guangdong-11-5 & China & & KC130184 \\
\hline & B-Jiangxi-11-4 & China & & KC130185 \\
\hline & AusCan & Australia & & EF990647 \\
\hline & TN340 & Taiwan & & EU375898 \\
\hline $\mathrm{MYaV}^{\mathrm{b}}$ & MB-10 & Brazil & & AY373028 \\
\hline
\end{tabular}

${ }^{\mathrm{a}}$ Sweet potato chlorotic fleck virus (SPCFV), ${ }^{\mathrm{b}}$ Melon yellowing-associated virus (MYaV), ${ }^{\mathrm{c}}$ Isolates analyzed in this study are shown in boldface.

ranged from $86 \%$ to $98 \%$. Especially, the Korean SPCFVSC20 isolate belonging to Group I showed $88.4 \%$ nucleotide sequence identity with the Uganda isolate, SPCFV-
Hoima 4; 73\% nucleotide sequence identity with SPCFVHG176, belonging to Group II; and 61\% nucleotide sequence identity with the closest Carlavirus, MYaV. The

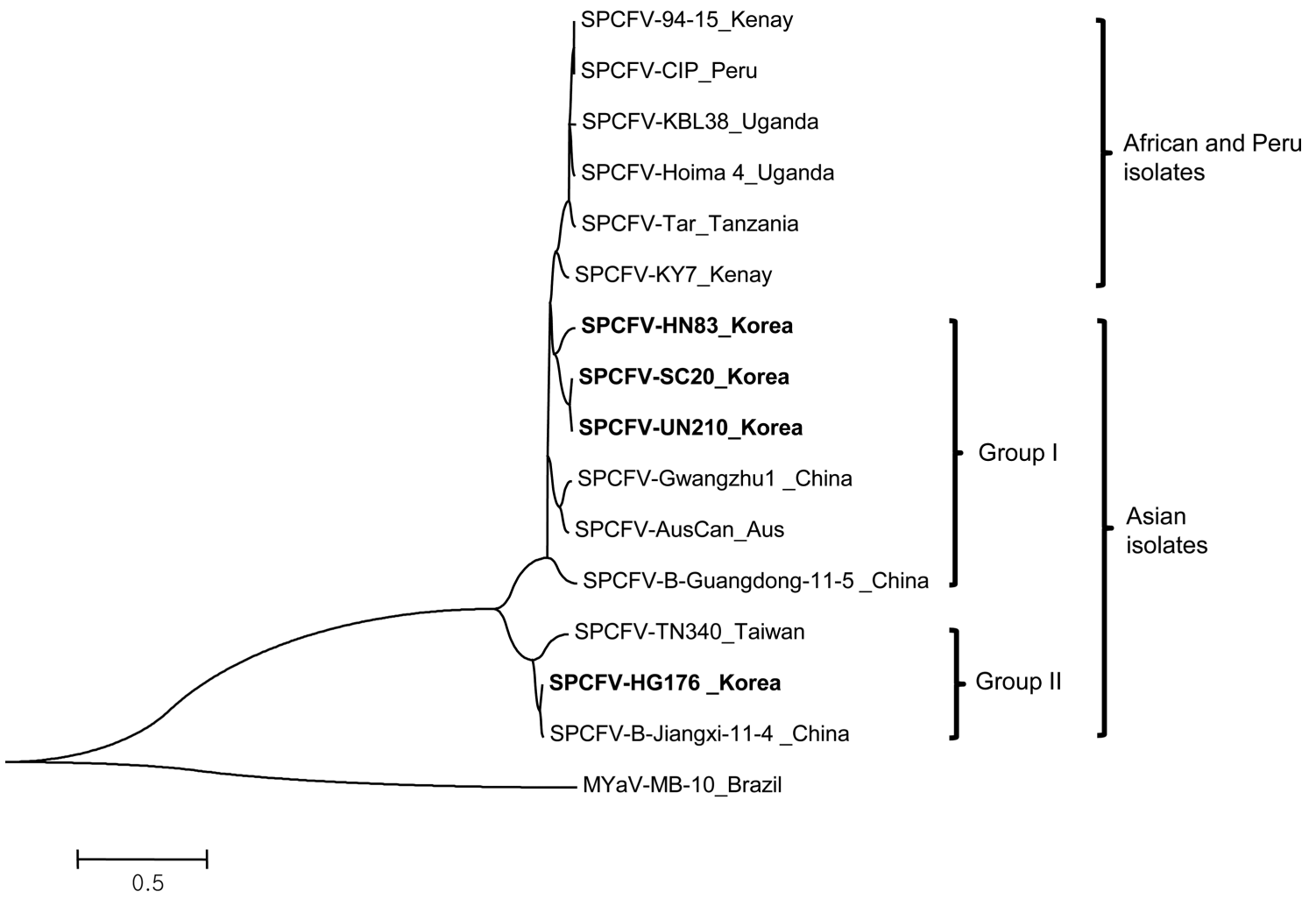

Fig. 1. Phylogenetic trees reconstructed using the complete and partial nucleotide sequences of the SPCFV isolates. Phylogenetic trees were reconstructed using the maximum-likelihood method in MEGA 6. 
Table 4. Nucleotide and amino acid sequence identities (\%) between Korean isolates SPCFV-SC20 and other SPCFV isolates infecting sweet potato

\begin{tabular}{|c|c|c|c|c|c|c|c|c|c|}
\hline Virus isolate & $\begin{array}{l}\text { Genome } \\
\text { (nt) }\end{array}$ & $\begin{array}{c}\text { 5'UTR } \\
\text { (nt) }\end{array}$ & $\begin{array}{l}\text { Rep } \\
\text { (aa) }\end{array}$ & $\begin{array}{l}\text { TGB1 } \\
\text { (aa) }\end{array}$ & $\begin{array}{c}\text { TGB2 } \\
\text { (aa) }\end{array}$ & $\begin{array}{l}\text { TGB3 } \\
\text { (aa) }\end{array}$ & $\begin{array}{l}\text { CP } \\
\text { (aa) }\end{array}$ & $\begin{array}{l}\mathrm{NaBp} \\
\text { (aa) }\end{array}$ & $\begin{array}{c}\text { 3'UTR } \\
\text { (nt) }\end{array}$ \\
\hline UN210-Korea & 98.4 & 100 & 98.7 & 100 & 100 & 97 & 99.7 & 99.2 & 100 \\
\hline HN83-Korea & 88.5 & 93.8 & 93.1 & 91.3 & 97.2 & 92.5 & 97.7 & 94 & 98.1 \\
\hline Hoima 4-Uganda & 88.4 & 96.8 & 92.9 & 91.3 & 96.3 & 86.6 & 96 & 93.2 & 98.1 \\
\hline KBL38-Uganda & 88.4 & & - & - & - & - & 95.7 & 88.7 & 96.2 \\
\hline 94-15-Kenay & 88.7 & - & - & - & - & - & 95.7 & 91.7 & 98.1 \\
\hline Tar-Tanzania & 88.7 & - & - & - & - & - & 95.3 & 92.5 & 98.1 \\
\hline CIP -Peru & 88.7 & - & - & - & - & - & 95.7 & 91.7 & 98.1 \\
\hline KY5-Kenay & 89.5 & - & - & - & - & - & 96.7 & 91 & 94.2 \\
\hline Gwangzhu1-China & 88.5 & - & - & - & - & - & 96.3 & 90.3 & 98.1 \\
\hline AusCan -Aus & 86.3 & - & - & - & - & - & 95.7 & - & - \\
\hline B-Guangdong-11-5-China & 85.9 & - & - & - & - & - & 95.7 & - & - \\
\hline HG176-Korea & 73.2 & 90.8 & 78.4 & 77.6 & 89.8 & 68.7 & 93.3 & 77.4 & 96.2 \\
\hline B-Jiangxi-11-4-China & 76.5 & - & - & - & - & - & 92.6 & - & - \\
\hline TN340-Taiwan & 77.6 & - & - & - & - & - & 91.3 & 78.9 & 98.1 \\
\hline MB-10-Brazil* & 61.3 & - & - & 52.6 & 69.7 & 24.6 & 61.9 & 46.7 & 69.1 \\
\hline
\end{tabular}

*MYaV (Melon yellowing-associated virus) as an outgroup

complete genome sequence of Group II SPCFV isolates (HG176) was determined in this study for the first time.

Regarding the deduced aa sequences of six individual proteins, the aa sequence identity in CPs between Group I and Group II was over $90 \%$, whereas the identities in other proteins were less than $80 \%$. The Korean SPCFVSC20 isolate showed a relatively high aa sequence identity (91-100\%) with Group I, including the Uganda isolate, SPCFV-Hoima 4. However, the Korean SPCFV-SC20 isolate showed $69-93 \%$ aa sequence identity with Group
II, including the Korean isolate, SPCFV-HG176. Further, the Korean SPCFV-SC20 isolate showed low aa sequence identities $(61 \%$ and $47 \%$ in CPs and NaBp region, respectively) with those of MYaV.

According to a report by the International Committee on Taxonomy of Viruses (ICTV), criteria for species classification of the family Betaflexiviridae include less than $72 \%$ nucleotide identity (or $80 \%$ aa identity of the encoded proteins) in the CP or replicase genes (Adams et al., 2011). Two groups of SPCFV Korean isolates belong to the same

Table 5. Recombination in SPCFV isolates

\begin{tabular}{|c|c|c|c|c|c|c|c|}
\hline \multirow{2}{*}{$\begin{array}{l}\text { Recombination } \\
\text { event No. }\end{array}$} & \multirow{2}{*}{$\begin{array}{l}\text { Recombinant } \\
\text { isolate }\end{array}$} & \multicolumn{2}{|c|}{ Recombination site in genome } & \multirow{2}{*}{$\begin{array}{l}\text { Genes } \\
\text { affected }\end{array}$} & \multirow{2}{*}{ Parental isolates ${ }^{\mathrm{a}}$} & \multirow{2}{*}{$\mathrm{RDP}^{\mathrm{b}}$} & \multirow{2}{*}{ P-value ${ }^{c}$} \\
\hline & & start & End & & & & \\
\hline 1 & Hoima 4 & 744 & 4167 & Rep & HN83 $\times$ AusCan & MCS3 & $2.41 \mathrm{E}-04$ \\
\hline 2 & HN83 & 4521 & 4718 & Rep & SC20 $\times$ Hoima 4 & BS & $1.04 \mathrm{E}-05$ \\
\hline 3 & HN83 & 8725 & 8969 & $\mathrm{NaBp}$ & $\mathrm{SC} 20 \times$ AusCan & RBMCS3 & $9.30 \mathrm{E}-03$ \\
\hline 4 & HN83 & 6663 & 6860 & TGB1 & SC20 $\times$ Unknown & BS & $7.20 \mathrm{E}-03$ \\
\hline 5 & AusCan & 6786 & 6817 & TGB1 & Unknown $\times$ HN83 & $\mathrm{MC3}$ & $5.94 \mathrm{E}-03$ \\
\hline 6 & Hoima 4 & 2938 & 2972 & Rep & $\mathrm{SC} 20 \times \mathrm{HN} 83$ & $\mathrm{GC}$ & $2.16 \mathrm{E}-02$ \\
\hline 7 & HN83 & 1048 & 1254 & Rep & Unknown $\times$ Hoima 4 & $\mathbf{R S}$ & $3.07 \mathrm{E}-02$ \\
\hline 8 & HN83 & 2673 & 2679 & Rep & Hoima 4 × HG176 & N3 & $3.28 \mathrm{E}-02$ \\
\hline 9 & Hoima 4 & 7532 & 7833 & TGB3, CP & Unknown $\times$ HN83 & MCS & $6.69 \mathrm{E}-03$ \\
\hline 10 & $\operatorname{Tm} 37$ & 6836 & 6851 & TGB1 & HG176 × Unknown & S3 & $1.03 \mathrm{E}-10$ \\
\hline
\end{tabular}

a 'Parental isolates' indicates the most likely isolates among those analyzed; Major parent $\times$ minor parent. ${ }^{b}$ RDP4-implemented methods that supported the corresponding recombination site: R (RDP), G (GENECONV), B (BootScan), M (MaxChi), C (Chimaera), and S (SiScan), 3 (3Seq).

'The highest P-value among the RDP4-implemented methods is reported. The corresponding method is shown boldface. 
species to meet the criteria above.

Recently, the complete genome sequences of two SPCFV isolates (Tm37 and AusCan isolates) and other partial sequences have been reported, and phylogenetic relationships of SPCFV based on CPs and NaBp nucleotide sequences have been analyzed (Maina et al., 2016; Tugume et al., 2016). According to these reports, SPCFV isolates, including Korean isolates, can be divided into East African and Asian groups (Asian 1 and Asian 2) geographically.

Recombination has been shown to significantly contribute to virus diversity. To examine whether recombination events have occurred within the SPCFV isolates, we aligned full-length nucleotide sequences of seven isolates including four Korean isolates, using the Geneious method in Geneious Pro 8 and analyzed them using the RDP, GENECONV, BootScan, MaxChi, Chimaera, SiScan and 3Seq methods implemented in the RDP4 software with a highest acceptable P-value of 0.01 . In total, 10 potential recombinant events were detected by at least one of the methods (Table 5). However, most isolates seemed to be 'tentative' recombinants, as they were supported by less than four methods or one of the parental isolates was labeled as 'unknown'. No significant recombination was detected in seven isolates. Korean SPCFV isolate HN83 showed some recombination spots, however, it is likely that genetic exchange by recombination is infrequent in natural populations of SPCFV. Further analyses of genetic population structure of SPCFV with more diverse full-genome sequences of worldwide isolates will be required for in-depth understanding of the evolutionary history of SPCFV.

In conclusion, it is essential to understand the molecular variation of viruses when designing knowledge-based control strategies. This study reports the complete genome sequences of SPCFV Group II isolates (denoted Asian 2 group by Tugume et al., 2016) for the first time. However, all SPCFV isolates found in Korea were infected with multiple viruses. Further, these SPCFV isolates have not been shown to mechanically infect previously reported host plants (Aritua et al., 2009). To better understand the relationship between genetic variation and pathogenicity in Korean SPCFV isolates, full-length infectious clones of two divergent SPCFV isolates will be required to elucidate biological characteristics of the two groups, including symptoms and host range.

\section{Acknowledgments}

This research was supported by grants from the Agenda Program (PJ PJ01130602) of the Rural Development Administration and Agricultural Biotechnology Development
Program (iPET: No. 110034-05-5-HD110) from Ministry of Agriculture, Food and Rural Affairs of Republic of Korea.

\section{References}

Adams, M. J., Candresse, T., Hammond, J., Kreuze, J., Martelli, G. P., Namba, S., Pearson, M. N., Ryu, K. H., Saldarelli, P. and Yoshikawa, N. 2011. Family. Betaflexiviridae. In: Virus Taxonomy - Ninth Report on the International Committee on Taxonomy of Viruses. eds. by A. M. Q. King, M. J. Adams, E. B. Carstens and E. J. Lefkowitz, pp. 920-941. Elsevier Academic Press, London, UK.

Aritua, V., Barg, E., Adipala, E. and Vetten, H. J. 2007. Sequence analysis of the entire RNA genome of Sweet potato chlorotic fleck virus reveals that it belongs to a distinct carlavirus species. Arch. Virol. 152:813-818.

Aritua, V., Barg, E., Adipala, E., Gibson, R. W., Lesemann, D. E. and Vetten, H. J. 2009. Host range, purification, and genetic variability in Sweet potato chlorotic fleck virus. Plant Dis. 93:87-93.

Brunt, A. A., Crabtree, K., Dallwitz, M. J., Gibbs, A. J. and Watson, L. 1996. Viruses of Plants. Descriptions and Lists from the VIDE Database. CAB International, Wallingford, UK. $1484 \mathrm{pp}$.

Clark, C. A., Davis, J. A., Abad, J. A., Cuellar, W. J., Fuentes, S., Kreuze, J. F., Gibson, R. W., Mukasa, S. B., Tugume, A. K., Tairo, F. D. and Valkonen, J. P. T. 2012. Sweetpotato viruses: 15 years of progress on understanding and managing complex diseases. Plant Dis. 96:168-185.

Kim, J., Yang J. W., Kwak, H. R., Kim, M. K., Seo, J. K., Chung, M. N., Lee, H. U., Lee, K. B., Nam, S. S., Kim, C. S., Lee, G. S., Kim, J. S., Lee, S. and Choi, H. S. 2017. Virus Incidence of Sweet Potato in Korea from 2011 to 2014. Plant Pathol. J. 33:467-477.

Kwak, H. R., Kim, M. K., Chung, M. N., Lee, S. H., Park, J. W., Kim, K. H. and Choi, H. S. 2006. Virus diseases incidences of sweet potato in Korea. Plant Pathol. J. 22:239-247.

Kwak, H. R., Kim, M. K., Shin, J. C., Lee, Y. J., Seo, J. K., Lee, H. U., Jung, M. N., Kim, S. H. and Choi, H. S. 2014. The Current Incidence of Viral Disease in Korean Sweet Potatoes and Development of Multiplex RT-PCR Assays for Simultaneous Detection of Eight Sweet Potato Viruses. Plant Pathol. J. 30:416-424.

Maina, S., Edwards, O. R., de Almeida, L., Ximenes, A. and Jones, R. A. C. 2016. Complete genome sequences of the Carlavirus Sweet potato chlorotic fleck virus from East Timor and Australia. Genome Announc. 4:e00414-e00416.

Tamura, K., Stecher, G., Peterson, D., Filipski, A. and Kumar, S. 2013. MEGA6: Molecular Evolutionary Genetics Analysis version 6.0. Mol. Biol. Evol. 30:2725-2729.

Tugume, A. K., Mukasa, S. B. and Valkonen, J. P. 2016. Mixed infections of four viruses, the incidence and phylogenetic relationships of Sweet potato chlorotic fleck virus (Betaflexi- 
viridae) isolates in wild species and sweetpotatoes in Uganda and evidence of distinct isolates in East Africa. PloS One 11:e0167769.

Untiveros, M., Fuentes, S. and Salazar, L. F. 2007. Synergistic interaction of Sweet potato chlorotic stunt virus (Crinivirus) with carla-, cucumo-, ipomo-, and potyviruses infecting sweet potato. Plant Dis. 91:669-676. 